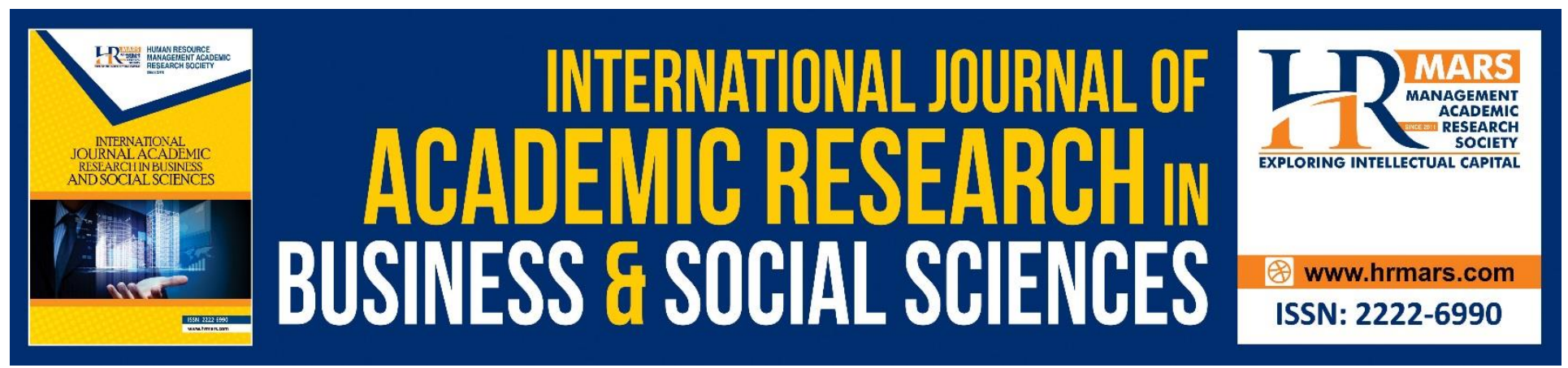

\title{
Theorizing Online Information Credibility among Teenagers
}

Norhayati Hussin, Hasnah Hashim, Wan Nor Haliza Wan Mokhtar, Nurul Syfa' Mohd Tokiran, Nordiana Nordin, Tengku Adil Tengku Izhar and Zaharudin Ibrahim

To Link this Article: http://dx.doi.org/10.6007/JJARBSS/v10-i11/8118 DOI:10.6007/IJARBSS/v10-i11/8118

Received: 07 September 2020, Revised: 29 September 2020, Accepted: 15 October 2020

Published Online: 08 November 2020

In-Text Citation: (Hussin, et. al., 2020)

To Cite this Article: Hussin, N., Hashim, H., Mokhtar, W. N. H. W., Tokiran, Nurul S. M., Nordin, N., Izhar, T. A. T., and Ibrahim, Z. (2020). Theorizing Online Information Credibility among Teenagers. International Journal of Academic Research in Business and Social Sciences. 10(11), 516-526.

Copyright: @ 2020 The Author(s)

Published by Human Resource Management Academic Research Society (www.hrmars.com)

This article is published under the Creative Commons Attribution (CC BY 4.0) license. Anyone may reproduce, distribute, translate and create derivative works of this article (for both commercial and non-commercial purposes), subject to full attribution to the original publication and authors. The full terms of this license may be seen

at: http://creativecommons.org/licences/by/4.0/legalcode

\section{Vol. 10, No. 11, 2020, Pg. 516 - 526}

http://hrmars.com/index.php/pages/detail/IJARBSS

JOURNAL HOMEPAGE

Full Terms \& Conditions of access and use can be found at http://hrmars.com/index.php/pages/detail/publication-ethics 


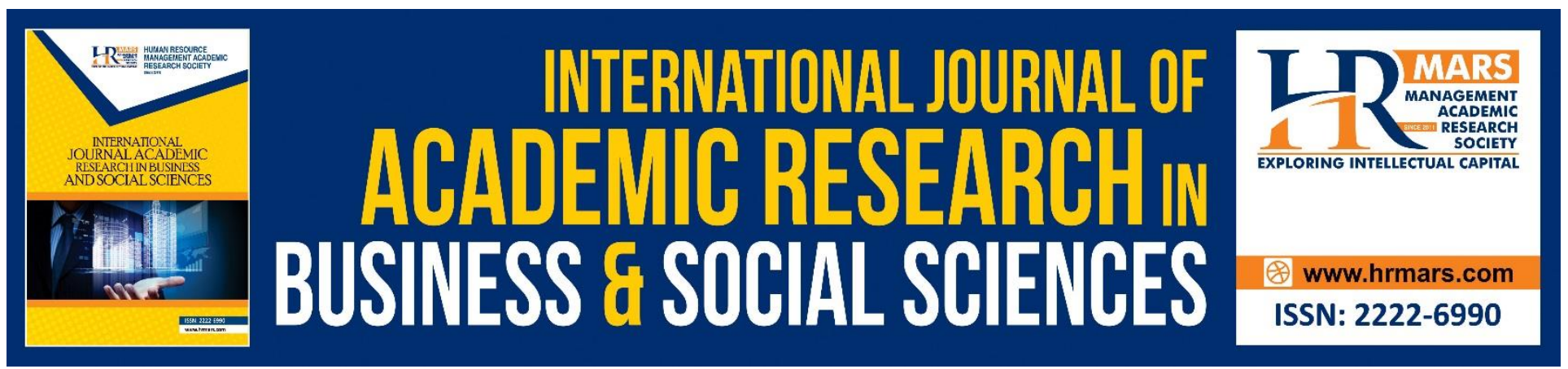

\title{
Theorizing Online Information Credibility among Teenagers
}

\author{
Norhayati Hussin, Hasnah Hashim, Wan Nor Haliza Wan Mokhtar, \\ Nurul Syfa' Mohd Tokiran, Nordiana Nordin, Tengku Adil Tengku \\ Izhar and Zaharudin Ibrahim \\ Faculty of Information Management, Universiti Teknologi MARA (UiTM), Selangor, Malaysia
}

\begin{abstract}
The society seems very hard to choose authentic and usable information with the right sources. It is maybe due to not knowing in determining precise and accurate information. The purpose of the study is to develop a model of online information credibility, which will provide the society with a guide to evaluation criteria to judge the credibility of online information use in their daily lives. The outcome also will able to facilitate government to educate society on how to use the information ethically to prevent misuse and misinterpret information that might affect national security. This paper postulated two objectives: i) to identify the evaluation criteria to justify the credibility of online information that able to provide trust among society in Malaysia (ii) to establish a framework on online information credibility among teenagers. Consequently, the study pursues to extend establish the theory by forming a model consisting variables which focus on young people's (a) social interaction, (b) cognitive status, and (c) identify/value negotiation and information creation during their contact with information. The proposed study adopted The Radical Change theory yielded a new model that will help understand youth information-related activities as a whole and their interrelationships. This study not just focus of personal routines or search sessions isolated from the context, but also to come out with a guide to help youth in choosing authentic and credible information.
\end{abstract}

Keyword: Library and Information Management, Information Credibility, Information sharing, Social Media

\section{Introduction}

The explosion of information either in the internet or news, the of trustworthiness, credibility as well as believably is severe. Contrasting with the ordinary news that has been validate and check by the editorial, the online news and information come from various sources either reliable or unreliable sources. Anyone who stay connect and access on the internet could post any kinds of information without checking and validating its data. As a result, rumour may end up in the news online and this kind of behavior could disturb its credibility and believability of information. Hassan et al. (2019) state the central problem that always occurs by the user in searching the information in the World Wide 
Web is trustworthy of information that user access from creation. For example, the current global pandemic, which is COVID19, there are much fake news and false information has been spread in no time. In Malaysia, the Ministry of Health warned the public regarding spread fake and unverified information on COVID19 when the disseminate of viral message on the particular areas should be avoided. Still, it is falsely claimed because the Ministry of Health already detects earlier (The Strait Times, 2020). The reader of online news could unable to identify fact from fiction and may admit the online cintent as the things that unquestionable true. Actually, it is necessary to assessing the perception of reader regarding issues on credibility and trustworthiness of information and to examine whether they genuinely believe on what they read without concern on the credibility of the information itself. In Malaysia, there is limited literature related to information credibility. Hence, this study intends to fulfil the stark gap by adopting the radical change theory to assess the youth information behaviour on online information to examine the evaluation criteria of information credibility. Radical change theory frequently uses in research related to Information Technology (IT) use such in the process of IT transformation, an associate of social integration and political-economic solution. This theory is based on the digital age principles of interactivity, connectivity and access are connected to understanding the significant changes in the digital age. It is expanded in this study through the creation of characteristics that address how youth think and assess the credibility of online information itself.

According to the Malaysian Communications and Multimedia Commission (2018), Internet users in Malaysia, approximately is $87.4 \%$, and most of them is a teenager. Nevertheless, no guideline could help them to ascertain accurate and reliable information and also exact and reliable sources. With this number of the internet population, the study on online information credibility is significant to the country. Therefore,this study would like to focus on youths because the most devoted and enthusiastic internet user as well as frequently absorb the online news rather than printed medium. This research relates to the government policy of No.9 or the 12 NKEA (National Key Economic Areas), i.e. the communications contents and infrastructure. The framework for Information Credibility resulted from this research can be used by policymakers at The Malaysian Communications and Multimedia Commission (MCMC) and federal level as a guideline for future decision making on information used for the public and society. Due to The Communications Content and Infrastructure (CCl) sector extents, a widespread ecosystem is covering network, content, applications, services and devices. Government through internet application can be served to the public such as disseminating information, policy, services and so on. Based on the comprehensive framework which will be developed to facilitate the society to search, analyze, and evaluate the right and accurate information. Therefore, the purpose of this paper is to come out with the appropriate framework of online information credibility of teenagers that could be used by other researchers, academician or information practitioner as reference for future research.

\section{Literature Review}

There is a various definition of credibility. In common, the scholarly examination of credibility is possibly amongst the oldest lines in communication research (Griffin, 2009; Liu, 2003). The research on credibility has a long history and has been interdisciplinary. In sum, different researchers or scholar exploited different definitions of credibility. Commonly, credibility is defined as the authenticity of the information. Society's view the credibility based on numerous different concepts 
INTERNATIONAL JOURNAL OF ACADEMIC RESEARCH IN BUSINESS AND SOCIAL SCIENCES Vol. 10, No. 11, 2020, E-ISSN: 2222-6990 @ 2020 HRMARS

such as objectivity, accuracy, reliability and timeliness. They rely on diverse cues of the source, social reputation, area and knowledge. To which degree of a credibility signal is used depends strongly on the decision-making condition. People seek information for a variety of purposes, especially for power, for comfort, for learning something new, and for knowledge to act and solve problems. However, not all online information is reliable and useful to users. Viewers must filter out the information received, it is not enough to simply receive and store the information without distinguishing between useful information and vice versa (Asad and Sri Devi, 2014; Wathen and Burkell, 2002).

Credibility defines as a judgment made by a receiver concerning the believability of a talker (O'Keefe, 1990, pp. 130-131). Many rely on the above discussion; hence the definition should also appropriate to be used in organization as well as individuals (Gass and Seiter, 2007). This description helps to reveal that credibility is a very complex concept, interdependent on many factors, and encompasses multiple dimension (Eisend 2006; Burgoon, Burgoon and Wilkinson, 1981). From another point of view, Garrison (2003) stimulated that the study of credibility is aspired by the component of individual attitudes towards technologies. Therefore, the need for research on credibility is due to the emergence of communication technology as the information received becomes increasingly difficult for the recipient to trust (Sbaffi and Rowley, 2017; Eggg et al., 2001; Tseng and Egg, 1999).

Studies on credibility constantly start when a different medium of sharing information arises; it effects on existing media (Liu, 2003). It has started long back when people worries in the newspaper industry. Then, the number of people increase to change to radio for news and the people depend on television for news and as a result arising number of studies on credibility as a medium in deliver news (Johnson, Kaye and Barbara, 2015). Nowadays, the arrival of Information, Communication and Technology (ICT) especially internet is influence on our everyday life (Eastin, 2001; Bhalla (2019). Since the 1980s, the development of the Internet has been tremendous growth as compared to any other communications medium. The evolution even faster than the development of the radio, television, telephone, or even cellular telephones (Cascio and Montealegre, 2016; Fogg et al., 2001). The main reason of the growth most probably because of vast support of the development of Internet technologies, the fast acceptance of Internet usage among public and the better administration of Internet resources (Alivi, Ghazali, Tamam, \& Osman, 2018).

The concept of credibility has revived significant attention as soon as the Internet emerged and began providing a platform of communication in an interactive environment of content in the internet allowed users to searching and seeking information and interact with others in many ways possible (Hilligoss \& Rieh, 2008). Moreover, the existence of the Internet in the communication boosts up the method of delivering information by offering interactive support everywhere in the world, and Malaysia is no exception (Omar 2017). Distribution and growing dependence on the Internet has also inspired researchers to study the credibility of online news in comparison to traditional media around the globe in the diverse area of specialization (Alivi, Ghazali, Tamam, \& Osman, 2018).

\section{Evaluation Criteria of Information Credibility}

The digital literacy effort is to understanding which skills required to evaluate the value or credibility of the information. It is becoming a crucial primary point for the digital literacy area of the subject. This is primarily the same purposes for assessing the information content in other channels of 
INTERNATIONAL JOURNAL OF ACADEMIC RESEARCH IN BUSINESS AND SOCIAL SCIENCES Vol. 10, No. 11, 2020, E-ISSN: 2222-6990 @ 2020 HRMARS

communication (Omar, 2017). Based on that, the literature classifies five common principles that users should equipped for them qualify in evaluating of online information: authority, objectivity, accuracy, currency, and coverage or scope (Asad and Sri Devi, 2014). Accuracy refers to the amount to which a Web site is free from mistake or fault, and this includes the information can be tested offline, and the reliability of the information on the site. On the authority perspective, a Web site is a judge by mentioning who authors the site and the contact information is provided of the person or organization that responsible by also stating their credentials, qualifications, and affiliations. Besides, the web also must provide a reliable source. Objectivity contains recognizing the purpose of the site and whether the information provided is point or opinion. For the currency, it states the information must be current. Meanwhile, the coverage refers to the completeness or depth of the information provided on the site. These recommendations need a variety of activities on the part of users, from simple visual inspection of a Web site to more laborious information verification and triangulation efforts.

Undeniably, according to Flanagin and Metzger (2013), many studies have found that users are not always thorough in checking the accuracy of the information they acquire online. Furthermore, in their series of studies, Metzger and Flanagin discovered there are five recommended criteria for the Internet users measure the credibility of the information they find online. From the data they collected across three years of the studies from the year 1999 to 2001 based on sample consists of college students and general adult internet users, they found that the five criteria for information credibility are accuracy, authority, objectivity, currency and coverage. Respondents were questioned to show how frequently they performed nine behaviours when visiting Web sites. Specifically, they were asked on the currency in which, how regularly they check to see if the information is up-to-date on the web. On the objectivity, the respondents were asked on how they consider whether the views represented on a site are facts or opinions. The questions on the coverage are how they check to see that the information is complete and comprehensive. Meanwhile, question-related to accuracy, the respondent was asked on how they look for other sources to endorse the information on a site. On the authority, the respondents were asked on how they check to see who the author of the web site is; and how they verify the author's qualifications or credentials. The respondent was also being asked whether or not they check to see whether the contact information for the author or organization is provided on the site. And look for whether or not the site has an official stamp of approval or a commendation as of someone they recognize.

Typically, previous researcher discovered that most people avoid to be dependent online information in the media because of its credible. Nowadays, the advancement of technology make people relied to internet and has become major source of news and information. However, the issues on privacy, content accuracy and reliability and other related issues become public concern and some observers mention the problem on online news will keep arise in the future (Abdulla, Garrison, Salwen, Driscoll, and Casey, 2002). Therefore, credibility is crucial for the Internet. Lu and Andrew (2006) state internet news is overflowing and it also readily accessible nowadays. People are seeking for information on the Internet instead of the traditional ways. The opportunity in access to information through internet in a quick manner and can retrieve at any time when they need it. Due to the nature of the Internet such as anyone can be an author without disclosing their information, so there are several obstacle to stop people from publishing in the internet. As a result, this situation lead concern on 
fake and false reference and any types of information forged. Moreover, the number of information in the internet is overflow and increased. The internet has become the virtual warehouse and the redundant of information available in the online media as well as traditional media. All these factors could create a possibility for false information, thus theoretically professed credibility away from proper care. Unexpectedly, people preserve on spread rumours on social media, email, website, blog, via mobile phone application such WhatsApp, Viber, wechat so on and so forth even though the authoritative has warned the society not to do so. Is society does not bother accurate information?

Asad and Sri Devi (2014) proposed in their paper the significance of factors to evaluate the credibility of information are including accuracy, authority, aesthetics, professionalism, popularity, currency, impartiality and quality. The aesthetic is refer to people perception towards credibility whereby the visual design preferences such as layouts, colour, images, fonts, or presentation of the data has a positive effect on online information credibility. This factor is quite important among the youth as the colour, image, etc. affect the body function, mind and emotion, and it could affect the judgment. Professionalism and popularity are mostly referred to most credential, and well-known site refer by users. Meanwhile, impartiality refers to the unbiased site, and quality is whether the site is reviewed by other credential author or organization.

Arise number of adult in using the internet in searching and reading online news continuously growth. The current number of internet user has estimated about 3.9 billion around the world (Statista, 2019). Statista (2019) reported the most significant online population at 829 million users in China, while India at 560 million and the United States 293 million. With the most significant number of population show, the Internet widely used by all population in the world. Other studies have exposed similar development in the use of the Internet, the World Wide Web, and other online information resources (for example, Nielsen Media Research, 1999; see Jupiter Media Metrix, 2001). The issue that has appeared and become a huge discussion among researcher in this evolution is the trustworthiness of new information technologies and new media news delivery systems. The new information delivery systems have led to growing public trust as the system easily can widespread access to personal information, property ownership records, and residential telephone numbers. Pryor \& Grabowicz (2001) stated one in three media Web Sites already post in their privacy policies regarding information both voluntarily by users. However, even though this media Web Sites post on privacy policies but those policy is too long and almost not complete. Usually, this privacy polices serve as legal alibi to the Web Sites rather than actual information sources.

Nowadays, Internet news is lavish and available at any time (Lu and Andrews, 2006). The amount of information is growth enormously, and the Internet has turning as huge information storehouse. So many readers are getting the chance to getting information via the Internet rather than traditional ways (Eastin, 2001). This situation would trigger the false quotation of information and other kinds of information forged. Therefore, the needs to have proper care of information credibility, such as providing a good guideline, is very much significant.

\section{Information Behavior of Teenagers based on Radical Change Theory}


Nowadays, there are a variety of information behaviours of teenagers, for example information seeking, using, sharing, and creating. Anyhow, there is little evidence to shows that the ways how youth should interact in the era of digital. There is almost none theoretical framework that sufficiently illuminates the behaviour of teenagers towards online information towards a holistic viewpoint. To build the empirical and theoretical gaps in the field of Information Behavior, this paper would like to create a theoretical framework of online credibility among teenagers to study information behaviour. The proposed study is intended to apply and further development of the theory of Radical Change. The paper embracing the theory to research, and the Radical Change Theory directed the development of the research questions and the research design incorporated the theory to provide structure to the systematic data collection and analysis. At the end, the theory will be informed and modified according to the study results.

Radical Change Theory is introduced by Eliza T. Dresang in the year 1990s. This theory proposed three digital age philosophies that describe changes in youth behaviour and information resources in the digital age known as interactivity, connectivity and access. This theory has been applied by many researchers to study information behaviour among youth. A typology with three forms of changes, each with indicators, operationalizes the theory for identification/ explanation of changes in information resources.

\section{Findings and Recommendations}

To establish the theoretical framework for this study, numerous theories and framework will be discussed. The preliminary fieldwork will be apply to refine the conceptual framework to make sure and confirm on the actual phenomenon of online information credibility among youths. Hence, the main contribution of the study is the establishment of the empirical-based model for online information credibility among teenagers. The model developed from the study can be used as a guideline for assessing online information credibility instrument. To date, studies investigating on credibility of online information from young adult perspectives have received little attention. The study will provide empirical data of the profile of online information credibility assessment for society and federal ministries uses.

The conduct of the study involved mixed-method approach which combines qualitative and quantitative. The expected outcome of the qualitative approach would be the dimensions of the online information credibility deemed essential for a social setting. The outcome of the quantitative approach would be the validated instrument which can be used by researchers to investigate similar topic but in different settings. This study will create an empirical-based framework for measuring online information credibility. The framework contains all the vital and critical factor in measuring online information credibility for society. Prior to the conduct of this study, there has yet any empirical-based framework which can be used for studying and measuring online information credibility in Malaysia.

The framework, when adopted and practice, will reduce misinterpretation, misuse, misconduct or wrong information that might contribute the country into chaos. This research proposed a guideline to justify information credibility for society uses. It helps to improve the social understanding towards the credibility of the information. It will avoid the society from misuse, misinterpret, distribute or 
INTERNATIONAL JOURNAL OF ACADEMIC RESEARCH IN BUSINESS AND SOCIAL SCIENCES Vol. 10, No. 11, 2020, E-ISSN: 2222-6990 @ 2020 HRMARS

share inaccurate information among them. The framework should be of interest to the researchers focusing on this topic. In addition, other researchers may also be interested in validating the framework in a different context as below:

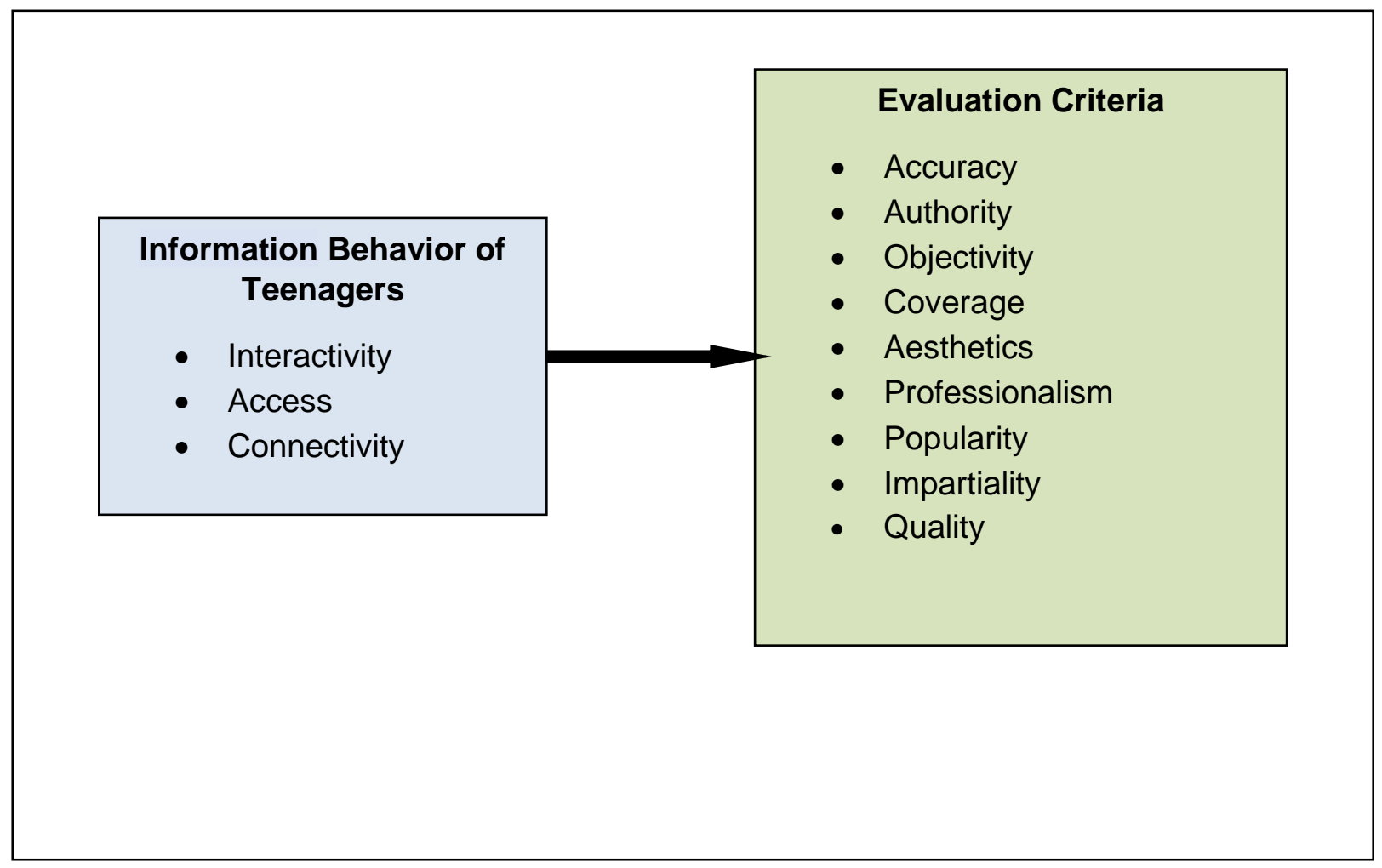

Figure 1: Conceptual Framework on Online Information Credibility of Teenagers

\section{Conclusion}

In a nutshell, the online information credibility of a teenager should be a measure to identify the skill and knowledge of teenagers in evaluating the credibility of information online. This empirical-based model will assist the teacher, lecturer or trainer for assessing the skill and knowledge of the teenagers in seeking the information through online. The teenager needs to acquire the skills in information management and in the use of information tools and databases that will lead them in searching the accurate information sources that related to their studies and daily activities (Kadir et al., 2018). The elements on online information credibility of teenagers will be used to describe what kind of elements used by a teenager when they are searching the information online. This model will assist the teenagers in finding the right information at the right location via the Internet. The appropriate information will help them gaining only the right information and can deliver to their friends who only read the fake information.

Even though there is much fake information on the Internet but with the appropriate skill and knowledge will assist teenagers in identifying the credibility of information online. This model significantly contributes to improving the skill of teenagers in searching and seeking online information as well as gain the right information for their academic task. The right information will 
INTERNATIONAL JOURNAL OF ACADEMIC RESEARCH IN BUSINESS AND SOCIAL SCIENCES Vol. 10, No. 11, 2020, E-ISSN: 2222-6990 @ 2020 HRMARS

provide the good and quality of work specially related to their study. The other researcher that has an interest in this study can extent this research on the different category of people and not focus on the teenagers only. This model also can assist the academic institution in assessing the credibility of online information and used it for their academic task or assignment.

\section{Acknowledgement}

This article is financially supported by:

1) Faculty of Information Management UiTM, Selangor, Malaysia

2) DUCS Grant, IRMI Universiti Teknologi MARA Cawangan Selangor. Reference no: UITMSEL (P1 5/4) (005/2018).

\section{Corresponding Author}

Norhayati Hussin.

Faculty of Information Management, Universiti Teknologi MARA (UiTM), Selangor, Malaysia.

Email: yatihussin@uitm.edu.my

\section{References}

Abdulla, R. A., Garrison, B., Salwen, M., Driscoll P., Casey D. (2002). The credibility of newspaper, television news and online news. Journalism and Mass Communication. Retreived June 2019, from:

http://citeseerx.ist.psu.edu/viewdoc/download?doi=10.1.1.556.4841\&rep=rep1\&type=pdf

Alivi, M. A., Ghazali, A. H. A., Tamam, E., \& Osman, M. N. (2018). A Review of New Media in Malaysia: Issues Affecting Society. International Journal of Academic Research in Business and Social Sciences, 8(2), 12-29.

Shah, A. A., and Ravana, S. D. (2014). Evaluating Information Credibility of Digital Content using Hybrid Approach. International Journal of Information Systems and Engineering (online), Volume 2, Issue 1, p. 92-99.

Bhalla, P. (2019). How Has The Internet Changed Our Lives?. Retrieved April 2020, from: https://360.shiprocket.in/blog/how-internet-changed-our-lives/

Burgoon, M., Burgoon, J. K., and Wilkinson, M. (1981). Newspaper Image and Evaluation. Journalism quarterly, 58(3), 411-433.

Cascio, W. F., and Montealegre, R. (2016). How Technology Is Changing Work and Organizations. Annual Review of Organizational Psychology and Organizational Behavior 3(1):349-375. DOI: 10.1146/annurev-orgpsych-041015-062352

Eastin, M. S. (2001). "Credibility Assessments of Online Health Information: The Effects of Source Expertise and Knowledge of Content". Journal of Computer-Mediated Communication, 6(4).

Eisend, M. (2006). "Source Credibility Dimensions in Marketing Communication - A Generalized Solution". Journal of Empirical Generalizations in Marketing Science, 10(1), 1-33 Fogg, B. J. (2002). Persuasive Technology: Using Computers to Change What We Think and Do. Morgan Kaufman: New York, NY.

Fogg, B. J., Soohoo, C., Danielson, D. R., Marable, L., Stanford, J., and Tauber, E. R. (2003), "How do users evaluate the credibility of web sites? A study with over 2,500 participants", Proceedings of the 2003 Conference on Designing for User Experiences, San Francisco, CA, USA, pp. 1-15. 
INTERNATIONAL JOURNAL OF ACADEMIC RESEARCH IN BUSINESS AND SOCIAL SCIENCES Vol. 10, No. 11, 2020, E-ISSN: 2222-6990 @ 2020 HRMARS

Fogg, B. J., Marshall, J., Laraki, O., Osipovich, A., Varma, C., Fang, N., Paul, J., Rangnekar, A., Shon, J., Swani, P., and Treinen, M. (2001), "What makes web sites credible? A report on a large quantitative study", Proceedings of the SIGCHI Conference on Human Factors in Computing Systems, Seattle, Washington, USA, March 31-April 4, pp. 61-8.

Fogg, B. J., Marshal, J., Osipovich, A., Varma, C., Laraki, O., Fang, N., Paul, J., Rangnekar, A.,Shon, J., Swani, P., and Treinen, M. (2000), "Elements that affect web credibility: early results from a self-report study", Proceedings of ACM CHI '00 Extended Abstracts on Human Factors in Computing Systems, The Hague, The Netherlands, pp. 287-8.

Gass, R. H., and Seiter, J. S. (2007). Persuasion, social influence, and compliance gaining (3rd ed.). Boston: Pearson Education, Inc.

Garrison, B. (2003). The perceived credibility of electronic mail in newspaper newsgathering. Paper presented at the Newspaper Division, Association for Education in Journalism and Mass Communication conference.

Griffin, E. (2009). A first look at communication theory (7th ed.). New York: McGraw-Hill. Hassan, Z., Hussin, N., Hashim, H., \& Tokiran, N. S. M. (2020). Information Seeking in Knowledge Society: Choose Right from Wrong. International Journal of Asian Social Science, 10(3), 151-158.

Hilligoss, B., and Rieh, S. Y., 2008. Developing a unifying framework of credibility assessment: Construct, heuristics, and interaction in context. Information Processing and Management, 44(4), 1467-1484.

Johnson, T. J., Kaye, B. K. (2015). Reasons to believe: Influence of credibility on motivations for using social networks. Computers in Human Behavior 50, p.544-555

Kadir, M. R. A., Johari, N. I. S., \& Hussin, N. (2018). Information Needs and Information Seeking Behaviour: A Case Study on Students in Private University Library. International Journal of Academic Research in Progressive Education and Development, 7(3), 226-235.

Liu, Z. (2003). Perception of credibility of scholarly information on the web. Information processing and management, 40(2004), 1027-1038.

Lu, H., and Andrews, J. E. (2006). College Students' Perception of the Absolute Media Credibility about SARS-Related News during the SARS Outbreak in Taiwan. China Media Research, 2(2), 85-93. Malaysian Communications and Multimedia Commission. (2018). Internet User Survey 2018. Retrieved June 2019, from:

https://www.mcmc.gov.my/skmmgovmy/media/General/pdf/Internet-Users-Survey2018.pdf

Metzger, M. J. and Flanagin, A. J. (2013). “Credibility and trust of information in online environments: the use of cognitive heuristics. Journal of Pragmatics, 59; p:210-220. O'Keefe, D. J. (1990). Persuasion Theory and Research. Newbury Park, CA: SagePew Omar, B. (2017). online news production, consumption and immediacy: The remediation

Perspective. Malaysian Journal of Communication, 33(3), 250-266. doi:10.17576/JKMJC2017-3303-15.

Pryor, L., \& Grabowicz, P. (2001). Privacy disclosure on news sites low: Detailed study suggests new media needs to work on public trust. Online Journalism Review. Retrieved August 14, 2001 from http://ojr.usc.edu/content/story.cfm?id=595 
INTERNATIONAL JOURNAL OF ACADEMIC RESEARCH IN BUSINESS AND SOCIAL SCIENCES

Vol. 10, No. 11, 2020, E-ISSN: 2222-6990 @ 2020 HRMARS

Sbaffi, L., and Rowley, J. (2017). Trust and Credibility in Web-Based Health Information: A Review and Agenda for Future Research. Journal of medical Internet research, 19(6), e218. https://doi.org/10.2196/jmir.7579

Statista. (2019). Number of internet users worldwide until 2019. Retrieved April 2020, from: https://www.statista.com/statistics/273018/number-of-internet-users-worldwide/

Self, C. C. (1996). Credibility. In M. B. Salwen and D. W. Stacks (Eds.). An integrated approach to communication theory and research (pp. 421-441). Mahwah: NJ: Erlbaum

Rahim, S. (2020). Fake news spreading faster than Covid-19 in Malaysia. The Strait Times. Retrieved April 2020, from: https://www.nst.com.my/news/nation/2020/03/572006/fake-newsspreading-faster-covid-19-malaysia

Wathen, C. N., and Burkell, J. (2002) "Believe it or not: Factors influencing credibility on the web". Journal of the American Society for Information Science and Technology, 53(2), 134-144. 